\title{
Research on Assessment of Electric Power Company's Credit Capacity Based on AHP and Entropy Weight
}

\author{
Lin Jiao ${ }^{1}$ Cong Zhao ${ }^{2}$ and Qiaosha Li $^{3}$ \\ ${ }^{1}$ School of Continuing Education, Hebei Finance University, Baoding, 071000, China \\ ${ }^{2}$ Department of Finance, Hebei Finance University, Baoding, 071000, China \\ ${ }^{3}$ Science and Technology Financial Key Laboratory of Hebei Province, Hebei Finance University, \\ Baoding, 071000, China
}

Keywords: Credit capacity; Analytic hierarchy process (AHP); Entropy weight

\begin{abstract}
Evaluating the credit capacity of electric power enterprises not only need to reflect the value of the index information conveyed, but also consider the analyst's subjective judgment. This paper combined the weights which respectively reflect the information of these two parts. Distance integrated evaluation method is also used in this paper to calculate the evaluation results, which can make the decision more consistent with the practical decision process. A specific example demonstrates the proposed method is practical, feasible and effective.
\end{abstract}

\section{Introduction}

With the further development of electricity market reform, the power companies will be from government support, and relying on their own efforts to improve the credit capacity to attract investment and be access to credit support. Therefore, evaluating the credit capacity of electric power enterprises conduct impartially and objectively is very meaningful. The AHP and entropy weight method are both applied in this paper to respectively determine the subjective weights and objective weights. Then, the combined weights are used in the evaluation of credit capacity, which can consider both subjective and objective factors. The results show that the proposed method is reasonable $[1,2]$.

\section{Establishment of credit capacity index system}

Evaluating the ability of corporate credit involves many factors. A three-level index system is established in this paper, which is shown in Table 1 [3].

(1) Target level, which means that take a comprehensive evaluation for the credit capacity of power companies.

(2) Principle level, which is divided into two aspects including profitability $(\mathrm{C} 1)$ and solvency (C2).

(3) Index level, which is also divided into two aspects including seven concrete indicators.

Table 1. Credit capacity index system

\begin{tabular}{|c|c|c|}
\hline Target level & Principle level & Index level \\
\hline \multirow{2}{*}{$\begin{array}{c}\text { Credit capacity } \\
\text { evaluation index } \\
\text { system }\end{array}$} & Profitability $\mathrm{C} 1$ & $\begin{array}{c}\text { The total return on } \\
\text { assets } \mathrm{P} 1 \\
\text { Interest coverage ratio } \\
\text { P2 } \\
\text { Sales profit } \mathrm{P} 3\end{array}$ \\
\hline & Solvency C2 & $\begin{array}{c}\text { Current Ratio P4 } \\
\text { Accounts receivable } \\
\text { turnover P5 } \\
\text { Assets and liabilities } \\
\text { P6 } \\
\text { Inventory turnover P7 }\end{array}$ \\
\hline
\end{tabular}




\section{Determination of index weight}

When the weight of $j$ th index is determining, these two following things need to be contained.

(1) The subjective weight $w_{j}$, which reflects the importance of judgment from experts and analysts. $w_{j}$ is composed of expert opinions and analysis subjective judgments through effective integrated and drawn.

(2) The objective weight $a_{j}$, which reflects the amount of information passed by indexes. $a_{j}$ is obtained through the objective comparison among indexes.

The comprehensive weight $\lambda_{j}$ is obtained by combing the subjective weight and objective weight, which is shown as follows:

$$
\lambda_{j}=w_{j} \cdot a_{j}, \quad j=1,2, \cdots, n .
$$

\section{The method of determining the subjective weight.}

The improved AHP method is used in this paper to determine the subjective weight. The main steps are shown as follows [4]:

(1) Establish hierarchical structure model as shown in Table 1.

(2) Construct the judgment matrix. The important degree related to the up level of each element in the same level will be compared, according to $1 \sim 9$ reading assignment. The judgment is obtained as $A=\left(a_{i j}\right)_{n \times n}$.

(3) Single-level sorting and consistency test. The largest eigenvalue and its corresponding eigenvectors in the judgment matrix $A$ will be normalized, which is the relative weight from the current level to the last level.

(4) Hierarchy total sorting, which means calculating the relative importance weights from all the factors of the same level to the top level. This process starts from the lowest level step by step. Supposing the last level $A$ has $m$ factors $A_{1}, A_{2}, \cdots A_{m}$, and theirs total level weight are respectively $a_{1}, a_{2}, \cdots, a_{m}$. Supposing the next level $B$ has $n$ factors $B_{1}, B_{2}, \cdots, B_{n}$, and theirs single-level sorting weight to $A_{j}$ are respectively $b_{1 j}, b_{2 j}, \ldots, b_{n j}$.

\section{The method of determining the objective weight}

The entropy weight method is used in this paper to determine the objective weight. The main steps are shown as follows [5]:

(1) Construct the index matrix $X$, and its factor $x_{i j}$ represents the $j$-th index value of the $i$ the company.

(2) Take the optimal value of each index $x_{j}^{*}$.

(3) Calculate the proximity $D_{i j}$ from $x_{i j}$ to $x_{j}^{*}$ which is defined as follows:

$$
D_{i j}=\left\{\begin{array}{ll}
\frac{x_{i j}}{x_{j}^{*}} & x_{j}^{*}=\max _{1 \leq i \leq m}\left\{x_{i j}\right\} \\
\frac{x_{j}^{*}}{x_{i j}} & x_{j}^{*}=\min _{1 \leq i \leq m}\left\{x_{i j}\right\}
\end{array} .\right.
$$

(4) Normalize $D_{i j}$ as $d_{i j}$ through $D_{i j} / \sum_{i=1}^{m} D_{i j}$.

(5) Calculate the entropy value of the $j$-th evaluation index $j$. The entropy value of evaluation indexes reflect the amount of system information. Its calculation equation is shown as follows: 
$H_{j}=-\sum_{i=1}^{m} d_{i j} \ln d_{i j}$

If all the $d_{i j}$ are the same, so $H_{j}=\ln m=H_{\max }$.

(6) Normalize $H_{i}$ by $H_{\max }$ as follows, which can obtain the entropy value of evaluation index.

$h_{j}=\frac{H_{j}}{\ln m}=-\frac{1}{\ln m} \sum_{i=1}^{m} d_{i j} \ln d_{i j}$.

(7) Determine the evaluation weight $a_{j}$ according to $h_{j}$.

$$
a_{j}=\frac{1}{n-\sum_{j}^{n} h_{j}}\left[1-h_{j}\right]
$$

\section{Evaluation of credit capacity index system}

He distance integrated evaluation method is used in this paper to obtain the final evaluation result. The main steps are shown as follow:

(1) Construct the weighted data matrix $Y=\left(y_{i j}\right)_{m \times n}$, where $y_{i j}=\lambda_{j} d_{i j}$.

(2) Determine the reference sample, which includes the optimal sample $Y^{+}$and the worst sample $Y^{-}$.

(3) Calculate relative proximity $C_{i}$ from the sample point to the optimal sample point.

$$
C_{i}=\frac{D_{i}^{-}}{D_{i}^{+}+D_{i}^{-}}=\frac{1}{\frac{D_{i}^{+}}{D_{i}^{-}}+1}, 0 \leq C_{i} \leq 1 .
$$

As can be seen from the above equation, when the value of $C_{i}$ is larger, the credit capacity of the company is better.

\section{Specific example and results analysis}

The proposed method are applied in evaluating the credit capacity of five power companies which are listed in Shanghai and Shenzhen Stock Exchange. The original data are shown in Table 2.

Table 2. The data of company credit capacity

\begin{tabular}{cccccccc}
\hline $\begin{array}{c}\text { Company } \\
\text { label }\end{array}$ & P1[\%] & P2 & P3 [\%] & P4 [\%] & P5[\%] & P6 [\%] & P7 [\%] \\
\hline 1 & 10.15 & 20.464 & 21.18 & 1.81 & 7.82 & 30.22 & 11.98 \\
2 & 4.26 & 33.653 & 15.64 & 2.07 & 8.82 & 11.03 & 23.25 \\
3 & 2.07 & 0.595 & 6.05 & 1.28 & 10.26 & 66.24 & 23.53 \\
4 & 0.93 & 1.119 & 9.81 & 1.46 & 2.11 & 38.78 & 10.34 \\
5 & 1.53 & 1.271 & 3.93 & 1.01 & 10.79 & 55.51 & 101.71 \\
\hline
\end{tabular}

According to experts' opinion and analysts' subjective judgment, 1-9 scaling method is used to determine the importance of each criterion level indicators for comparison. The results are respectively shown in Table 3, Table 4 and Table 5.

Table 3. The judgment matrix of A-C

\begin{tabular}{ccc}
\hline $\mathrm{A}$ & $\mathrm{C} 1$ & $\mathrm{C} 2$ \\
$\mathrm{C} 1$ & 1 & 3 \\
$\mathrm{C} 2$ & $1 / 3$ & 1 \\
\hline
\end{tabular}


Table 4. The judgment matrix of C1-P

\begin{tabular}{cccc}
\hline C1 & $\mathrm{P} 1$ & $\mathrm{P} 2$ & $\mathrm{P} 3$ \\
$\mathrm{P} 1$ & 1 & $1 / 5$ & $1 / 3$ \\
$\mathrm{P} 2$ & 5 & 1 & 3 \\
$\mathrm{P} 3$ & 3 & $1 / 3$ & 1 \\
\hline
\end{tabular}

Table 5. The judgment matrix of C2-P

\begin{tabular}{ccccc}
\hline C2 & P4 & P5 & P6 & P7 \\
P4 & 1 & $1 / 7$ & $1 / 3$ & $1 / 5$ \\
P5 & 7 & 1 & 5 & 3 \\
P6 & 3 & $1 / 5$ & 1 & $1 / 3$ \\
P7 & 5 & $1 / 3$ & 3 & 1 \\
\hline
\end{tabular}

The subjective weights are obtained according to Eq.(3), which is shown as follows:

$$
w=\left(\begin{array}{lllllll}
0.026 & 0.159 & 0.065 & 0.041 & 0.423 & 0.089 & 0.197
\end{array}\right) .
$$

As can be seen, experts and analysts subjectively think that accounts receivable turnover (P5), inventory turnover ratio (P7) and interest coverage ratio (P2) these three indexes are more important.

The objective weights are obtained according to Eq.(8), which is shown as follows:

$$
a=\left(\begin{array}{lllllll}
0.184 & 0.383 & 0.084 & 0.016 & 0.051 & 0.068 & 0.213
\end{array}\right) .
$$

As can be seen, the interest coverage ratio $(\mathrm{P} 2)$ and inventory turnover rate $(\mathrm{P} 7)$ these two indexes relatively reflect the large amount of information.

According to Eq.(1), the combined weights after being normalized is shown as follow:

$$
\lambda=\left(\begin{array}{lllllll}
0.034 & 0.430 & 0.039 & 0.005 & 0.154 & 0.043 & 0.296
\end{array}\right) .
$$

As can be seen, the interest coverage ratio (P2) and inventory turnover ratio (P7) these two indexes are more important, which is consistent with the experts' own subjective analysis.

According to Eq.(9), the value of $C_{i}$ and the evaluation ranking results are shown in Table 6. Table 6. The evaluation ranking results

\begin{tabular}{cccccc}
\hline $\begin{array}{c}\text { Company } \\
\text { label }\end{array}$ & 1 & 2 & 3 & 4 & 5 \\
\hline $\mathrm{Ci}$ & 0.452 & 0.648 & 0.125 & 0.027 & 0.398 \\
Rankings & 2 & 1 & 4 & 5 & 3 \\
\hline
\end{tabular}

As can seen from Table 6, the credit capacity of No.2 company is the best. No.1 and No.5 company have a better credit capacity. However, No.3 and No.4 company need to analyze the problems within their own, and take efforts to improve management, and actively seek credit support.

\section{Conclusions}

The improved AHP and entropy weight method are applied in evaluating the credit capacity of power companies, which can fully combine the subjective analysis from experts with the objective information. A specific example demonstrates the proposed method is practical, feasible and effective. 


\section{References}

[1] F. Lolli, A. Ishizaka, R. Gamberini. New AHP-based approaches for multi-criteria inventory classification. International Journal of Production Economics. Vol. 156 (2014), p. 62-74.

[2] Shin-ichi Ohnishi, Takahiro Yamanoi. On Fuzzy Priority Weights of AHP for Double Inner Dependence Structure. Procedia Computer Science. Vol 35 (2014), p.1003-1012.

[3] Jiř́ Franek, Aleš Kresta. Judgment Scales and Consistency Measure in AHP. Procedia Economics and Finance. Vol. 12 (2014), p.164-173.

[4] Xiaobing Yu, Shunsheng Guo, Jun Guo, Xiaorong Huang. Rank B2C e-commerce websites in e-alliance based on AHP and fuzzy TOPSIS. Expert Systems with Applications. Vol. 38 (2011), p. 3550-3557.

[5] Reza Eslamipoor, Abbas Sepehriar. Firm relocation as a potential solution for environment improvement using a SWOT-AHP hybrid method. Process Safety and Environmental Protection. Vol. 92 (2014), p. 269-276. 